\title{
Trivium
}

Revue franco-allemande de sciences humaines et sociales - Deutsch-französische Zeitschrift für Geistesund Sozialwissenschaften

29 | 2019

Regards croisés sur le prophète de l'Islam

\section{Das am Propheten orientierte Modell der Heiligkeit im Islam}

\section{Michel Chodkiewicz}

Traducteur : Bettina Engels et Nikolaus Gramm

\section{CpenEdition}

Journals

Édition électronique

URL : http://journals.openedition.org/trivium/6321

DOI : $10.4000 /$ trivium.6321

ISBN : 1963-1820

ISSN : 1963-1820

Éditeur

Les éditions de la Maison des sciences de l'Homme

\section{Référence électronique}

Michel Chodkiewicz, « Das am Propheten orientierte Modell der Heiligkeit im Islam », Trivium [Online], 29 | 2019, online erschienen am 17 Oktober 2019, abgerufen am 08 September 2020. URL : http:// journals.openedition.org/trivium/6321; DOI : https://doi.org/10.4000/trivium.6321

Ce document a été généré automatiquement le 8 septembre 2020.

\section{(c) $(1) \odot$}

Les contenus des la revue Trivium sont mis à disposition selon les termes de la Licence Creative Commons Attribution - Pas d'Utilisation Commerciale - Pas de Modification 4.0 International. 


\title{
Das am Propheten orientierte Modell der Heiligkeit im Islam
}

\author{
Michel Chodkiewicz \\ Traduction : Bettina Engels et Nikolaus Gramm
}

\section{NOTE DE L'ÉDITEUR}

Wir danken Herrn Michel Chodkiewicz für die freundliche Genehmigung, diesen Artikel in deutscher Übersetzung zu publizieren.

Nous remercions M. Michel Chodkiewicz de nous avoir accordé l'autorisation de traduire ce texte pour le présent numéro.

1 Hat Ibn Hanbal Melonen gegessen? Denjenigen gegenüber, die darauf brennen, eine kategorische Antwort auf diese Frage zu hören, muss ich meine Verlegenheit bekennen. Wenn man Ibn al-Jawzī (gest. $597 / 1200-1)^{1}$ glaubt, so »kaufte [Ibn Hanbal (gest. 241 / 855-6)] weder Granatapfel noch Quitte noch irgendeine Frucht außer der Melone«. Dann wissen wir das also, werden Sie denken. Einer überaus verbreiteten Tradition zufolge, der zahlreiche bedeutende Autoren anhingen, ${ }^{2}$ hat sich der Imam Ahmad allerdings strikt versagt, Melonen zu verzehren, weil er nicht wusste, wie der Prophet sie aß. ${ }^{3}$ Auch wenn ich mir nicht sicher bin, vermute ich, dass die historische Wahrheit bei Ibn al-Jawzī zu finden ist. Doch werde ich mich für die Zwecke der folgenden Ausführungen an die andere Version halten, denn sie illustriert auf eine Weise, die einem nicht-gläubigen Menschen lächerlich erscheinen mag, einen einzigen Aspekt des in der islamischen Kultur omnipräsenten Themas der imitatio prophetae.

Laqad kāna lakum fì rasūlì llāhi uswatun hasana. Dieser Koranvers, der übrigens Teil einer Sure mit einem ausgeprägten prophetologischen Charakter - Al-ahzāb (Koran 33:21) ist, ${ }^{4}$ begründet zweifellos das Paradigma, auf das sich jede denkbare Form von Vervollkommnung im Islam zu berufen hat. Dieser - in Schriften und Äußerungen so häufig auftauchende - Verweis kann Ausdruck wahren Glaubens sein. Natürlich kann er auch ein Ausdruck von Konformität sein, der Interessen, Berechnung oder Ängste 
verschleiert. Auf jeden Fall aber lässt sich die Geschichte islamischer Gesellschaften nicht verstehen, ohne zu berücksichtigen, was für eine wichtige Rolle diesem Verweis sowohl für die Herausbildung individueller und gemeinschaftlicher Normen als auch für die Definition des Ideals zukommt, dem diese Normen verpflichtet sind: Denn ganz gleich unter welchem Aspekt sich die imitatio prophetae präsentiert, stets hat sie die Form einer Asymptote. Sie muss darauf aus sein, sich der unübertrefflichen Fülle des "ausgezeichneten Vorbilds« immer weiter anzunähern, ohne es jemals zu erreichen.

3 Bei der 'āmma - den gewöhnlichen Gläubigen - wird die Imitatio oft einen recht äußerlichen Charakter behalten: Über die Einhaltung der Gesetzesformen hinaus, die sich aus dem Vorbild und den Vorschriften des Propheten ergeben und für alle verbindlich sind, wird sich der fromme Muslim bemühen, unter verschiedenen gleichermaßen zulässigen Verhaltensweisen diejenigen auszuwählen, die vom Propheten ausgezeichnet wurden, und folglich bestimmte Handlungsweisen, eine bestimmte Kleidung und bestimmte Nahrungsmittel bevorzugen. Dass eine solche Konformität auf einen reinen Konformismus hinauslaufen kann, ist mehr als offensichtlich. Dass sie einer endlosen Kasuistik Tür und Tor öffnet und dem flammenden Eifer der Neuerungsfanatiker das Feld überlässt, hat sich in der älteren und jüngeren Geschichte zur Genüge gezeigt. Doch Muhammad wurde von Gott geschickt, um die makārim al-akhlāq, die »edlen Tugenden «, ${ }^{5} \mathrm{zu} »$ vervollkommnen«, und die imitatio prophetae sollte sich nicht auf das gewissenhafte Befolgen augenscheinlicher Verhaltensweisen beschränken, deren Beispiel sich der Tradition entnehmen lassen. Sie sollte soweit möglich auch darauf ausgerichtet sein, das innere Sein des Gläubigen mit dem Vorbild des Propheten in Einklang zu bringen. Aus diesem Prinzip leitet sich zwar eigentlich kein System ethischer Werte $a b$ - diese finden sich schon im Koran formuliert -, wohl aber eine Repräsentationsweise dieser Werte, basierend auf der historischen Existenz eines sie verkörpernden Menschen.

Das sind also die beiden Aspekte der Treue zum »ausgezeichneten Vorbild « - wobei Ersterer eher für das Sozialverhalten, Letzterer eher für das ethische Verhalten von Bedeutung ist -, auf die sich die Aufmerksamkeit der Forschung am häufigsten konzentriert. Annemarie Schimmel, der wir ein Werk $^{6}$ verdanken, das auf bewundernswerte Art und Weise die zentrale Rolle des Propheten für die islamische Spiritualität herausstellt, greift selbst eine Interpretation von Armand Abel auf, in der die imitatio prophetae auf die Imitation "seiner Handlungsweisen und Tätigkeiten" reduziert wird. ${ }^{7}$ Allgemein kann man sagen, dass nur wenige Arbeiten genügend Sorgfalt darauf verwenden, die Person Mohammeds in Lehre und Glauben seiner Gemeinde $\mathrm{zu}$ beleuchten - um den Titel des 1917 erschienenen Buches von Tor Andrae aufzugreifen. ${ }^{8}$ Noch seltener aber sind die Arbeiten, die die Wichtigkeit der Bezugnahme auf den Propheten in Hagiologie und Hagiografie angemessen würdigen. Zwar wird die Idee vage und beiläufig zugelassen, doch bleibt sie eher folgenloses Lippenbekenntnis und wird nicht weiter entfaltet. Das gilt beispielsweise für ältere Werke wie Mystique musulmane von Gardet und Anawati (der Eintrag "walī» in der ersten Auflage der Encyclopédie de l'Islam von Bernard Carra de Vaux gibt diesbezüglich keinerlei Auskunft). Es gilt ebenso für Julian Baldicks Buch Mystical Islam (London 1989) oder für die 1985 in der Zeitschrift Islamochristiana erschienenen Aufsätze von Farūqī und Nizāāmī, die sich mit dem Begriff der Heiligkeit im Islam auseinandersetzen. ${ }^{9}$

5 Zwei aktuelle Kontroversen haben mich nun dazu gebracht, dieses Problem eingehender zu thematisieren. Die erste ist eine innermuslimische Kontroverse. Sie 
wurde in Ägypten durch die Praktiken der țarīga burhāniyya (des Sufi-Ordens) und vor allem die Lehren seines Gründers, des 1983 gestorbenen sudanesischen shaykh (Scheich) Muhammad 'Uthmān 'Abduh al-Burhānī, hervorgerufen. Pierre-Jean Luizard in Frankreich und Valérie Hoffman-Ladd in den Vereinigten Staaten haben die Streitpunkte und Wendungen dieser Debatte zusammengefasst. ${ }^{10}$ Ohne auf die Einzelheiten der scharfen Auseinandersetzungen einzugehen, die die Publikation der Tabri'at al-Dhimma fi Nușh al-Umma dieses shaykh ausgelöst haben (und später die Verbreitung von Schriften, die er angeblich einigen seiner Schüler noch post mortem auf Arabisch... und auf Deutsch! diktiert hat), sei darauf verwiesen, dass ein wesentlicher Vorwurf gegen seine Lehre der einer "Vergöttlichung des Propheten « ist. ${ }^{11}$

6 Die zweite ist eine wissenschaftliche und also höfliche Kontroverse - was, wie man weiß, nicht heißt, dass sie vollkommen friedlich wäre. Hier stehen sich unsere Kollegen Bernd Radtke und R. S. O'Fahey auf der einen Seite und Experten wie Fazlur Rahman, J. S. Trimingham, John O. Voll oder B. G. Martin auf der anderen gegenüber; ausgetragen wird sie um den Begriff der țariqa muhammadiyya, definiert als das Ziel einer „Vereinigung mit dem Geist des Propheten«. In einem unter dem Titel »Neo-Sufism reconsidered « in Der Islam erschienenen Artikel kritisieren Radtke und O'Fahey die These dieser Wissenschaftler, dass im 18. Jahrhundert - insbesondere mit Ibn Idrīs (gest. 1264 / 1897), Muḥammad al-Sanūsī, Ahmad al-Tijānī - ein "reformierter" Sufismus entstanden sei, der durch das Auftreten jenes sogenannten "muhammedanischen Wegs « gekennzeichnet sei, der, mit der Vergangenheit brechend, den Propheten ins vitale Zentrum seiner Hagiologie gestellt habe. ${ }^{12}$ Radtke und O'Fahey sehen diesen angeblichen "Neosufismus" hingegen in perfekter Kontinuität mit einer sehr alten Tradition, weil er etwa "die Entwerdung im Propheten« als entscheidende Etappe auf dem Lebensweg ansieht, der zur walāya (Heiligkeit) führt.

7 Diese beiden Kontroversen unterscheiden sich sicherlich gravierend. Die erste endete mit dem Bannfluch gegen den Häretiker. Die zweite - noch nicht abgeschlossene - stellt die üblicherweise anerkannten Ergebnisse einer historischen Untersuchung in Frage. Die Personen, deren Schriften oder Taten am Beginn dieser Debatten stehen - Ibn Idrīs oder Aḥmad al-Tijānī einerseits und Muhammad 'Uthmān andererseits -, weisen außerdem recht unterschiedliche Eigenschaften auf. Doch eine Grundhaltung teilen sie: Die Möglichkeiten des muhammedanischen Vorbilds erschöpfen sich aus ihrer Sicht nicht in den geläufigen Formen der aktiven Annahme der uswa hasana (dem »schönen Vorbild«). Die Person des Propheten ist in ihren Augen zugleich das, was man in Begriffen der Scholastik die "Formursache" (causa formalis) und die "Wirkursache" (causa efficiens) aller Heiligkeit nennen könnte. Die walāya besitzt in Muhammad zugleich ihre Quelle und ihre exemplarische Vollendung.

8 Persönlich bin ich allerdings davon überzeugt, dass diese Doktrin weder im 18. noch im 20. Jahrhundert neu war. Doch die Stichhaltigkeit des so verstandenen ProphetenVorbilds zu beweisen, ist keine leichte Sache. Man muss das Problem aus verschiedenen Perspektiven betrachten: insofern das prophetische Modell ein Vorbild für die Heiligen selbst ist; insofern es ein Vorbild für die Hagiologie, die Theorie der Heiligkeit, ist; und insofern es sich schließlich mehr oder minder bewusst der Hagiographie auferlegt, wodurch der Archetyp zum Stereotyp zu verkommen droht. In unseren Quellen finden sich diese drei Aspekte oft vermischt. Die Elemente eines Heiligenlebens können in Funktion dieses Modells umorganisiert worden sein, und derlei fromme 
Manipulationen ziehen, so sie entdeckt oder vermutet werden, die Authentizität der dieser Persönlichkeit zugeschriebenen Lehren oder spirituellen Erfahrungen in Zweifel. Der Historiker tröstet sich mit der Überlegung, dass auch die Wiederkehr eines Stereotyps niemals bedeutungslos ist, dass ihm, mit anderen Worten, auch die "goldene Legende« etwas zu sagen hat.

Wie dem auch sei, möchte ich mich an dieser Stelle darauf beschränken, einige Hinweise zu geben, auf einige Tatsachen oder Texte zu verweisen, auf die ich meine Überzeugung gründe. Was die geradezu magnetische Anziehungskraft der uswa hasana auf die Hagiographie und deren Folgen für das Bild des wali (des Heiligen) angeht, so erwähne ich sie nur zur Erinnerung. Ihre Auswirkungen sind normalerweise leicht zu bestimmen, selbst wenn überflüssige Details manchmal das Offensichtliche verhüllen. Aus diesem Grund muss man natürlich eher auf den wiederkehrenden Gebrauch der offenkundig von der Sira nabawiyya (Prophetenbiographie) angeregten Topoi achten als auf das isolierte Auftreten des einen oder anderen Topos. Ohne jeden Anspruch auf Vollständigkeit werde ich einige Charakteristika anführen, deren Signalcharakter für Spezialisten ein wohlbekanntes Signal erkennbar ist. Die Vorzeichen und Wunder, die mit der Geburt eines Heiligen einhergehen, gehören dabei zu den häufigsten. Insbesondere die Berichte, die sich auf die Gründer der țuruq (der »spirituellen Wege« oder Orden - Mehrzahl von țarīqa, A.d.Ü.) beziehen, beispielsweise auf 'Abd al-Qādir alJìlānī, Ahmad al-Rifā'̄ī, Bahā al-Dīn Naqshband oder 'Abd al-'Azīz al-Dabbāgh, sind reich an mirabilia, in denen sich ein außergewöhnliches Schicksal ankündigt. Ahmad alBadawīs Mutter erscheinen im Verlaufe ihrer Schwangerschaft hintereinander Abraham, Moses, Jesus, Muhammad, Ali und Hussein, die ihr den zukünftigen Ruhm ihres Sohnes prophezeien. Als er geboren wird, ist die Kaaba erleuchtet..$^{13}$ Und belustigt stellt man ganz nebenbei fest, dass die Biographen Muhammad Ibn 'Abd alWahhābs, jenes großen Gegners des Heiligenkults, der Versuchung des Mimetismus nicht widerstehen konnten. In einem vor einigen Jahren veröffentlichten wahhabitischen Werk kann man lesen, dass der Großvater dieses Imams des Tauhïd vor dessen Geburt im Schlaf ein Feuer sah, das aus seinem Nabel emporschlug und alle Wüsten erleuchtete. Er schloss daraus, dass seine Lenden einen Mann hervorbringen sollten, der die Völker führen würde. ${ }^{14}$

Eine weitere signifikante Eigenschaft, nämlich der Waisenstand, ist bei den awliy $\bar{a}$ (den Gottesfreunden [im Sinne von: Heiligen; A.d.Ü.]) überaus häufig anzutreffen. Auch ihre Kindheit verläuft oft nach dem Vorbild des Propheten. Puer senex oder das reife Kind: »Wann wusstest du, dass du ein Heiliger bist?«, wurde Jilānī gefragt - »Als ich zehn Jahre alt war«, antwortete dieser. Der Heilige hat ein ausgeprägtes Schamgefühl - dem Bauch seiner Mutter kaum entstiegen, bedeckt al-Rifā'î̀ sein Geschlecht mit seiner linken Hand,$-{ }^{15}$ er meidet Ablenkungen und Spiele, er hütet das Vieh. Er spricht ohne Umschweife: Wie der Prophet ist auch er amin, er flößt allen Vertrauen ein. Mindestens im Traum macht er Erfahrungen, deren offensichtlich läuternde Symbolik die Reinigung des Herzens Muhammads von Engelhand evozieren. Manchmal durchlebt er jene Episode aus der sìra sogar auf identische Weise. Davon berichten detailliert Yāfi'i Abū Rabī' al-Malaqī sowie die Salwat al-Anfās von Sīdī 'Umar al-Kattānī. ${ }^{16}$ Auch die Begegnung mit Bahīrā findet oft ihren Widerhall: Eine mysteriöse Gestalt, so wie der rätselhafte baqqāl, der Ibn al-Fārị̣ (gest. 632 / 1234-5) nach Mekka schickt, ${ }^{17}$ wurde von Gott über das Schicksal des künftigen wali in Kenntnis gesetzt, um ihn seiner Berufung zuzuführen. Oft handelt es sich um einen alten Mann; und es kommt nicht selten vor, 
dass dieser von der Vorsehung gesandte Greis, wie Bahīrā, ein Mönch ist. Die Rolle des rāhib (des Mönchs) in der Hagiographie bedürfte eines eingehenderen Kommentars. ${ }^{18}$

Der Rückzug - in eine Grotte, in die Wüste, auf Friedhöfe, in Ruinen - ist eine typische Etappe der Heiligen-Ausbildung. Zwar kann er - da die Prophezeiung eigentlich abgeschlossen ist - dort keine Offenbarung erleben, er wird aber mit jenen Traumvisionen belohnt, die den 46. und einzig noch offenen Teil der nubuwwa (der Prophezeiung) ausmachen. Er vernimmt dort ein hātif, eine übersinnliche Stimme. Darauf folgt der "Abstieg vom Berg" - im eigentlichen Wortsinn etwa für einen Abu alḤasan al-Shādhịili (gest. 657 / 1258), ${ }^{19}$ im metaphorischen Sinn für andere: Auf göttliche Weisung kehrt der wali zu den Menschen zurück, um sie zu führen. Im Laufe seiner Mission muss er Prüfungen bestehen. Er muss ins Exil gehen. Seine Verfolger werden schließlich zurückgeschlagen: Der Hidschra (dem Auszug) folgt die fath, die siegreiche Eroberung der Herzen.

Derlei Übereinstimmungen mit den Handlungsweisen des Propheten muss es nicht unbedingt an historischer Wahrheit mangeln. Doch die allzu offensichtlichen Homologien sind, zumal wenn sie sich in Serie ereignen, fast immer erfunden. Davon zeugt der Umstand, dass sie meist nur in späten Berichten Erwähnung finden und in älteren Quellen über die betreffende Person nicht auftauchen. Überdies ist $\mathrm{zu}$ bemerken, dass von den Homologien, die man seit dem 13. Jahrhundert häufig antrifft, in den ersten Sammlungen der Vitae sanctorum, wie dem Ṭabaqāt des Sulamī oder der Hilyat des Abū Nu'aim, noch keine Rede ist. Als fromme Lügen huldigen sie einer sie übersteigenden Wahrheit. Sie spielen für meine These allerdings keine Rolle und sind meines Erachtens eher geeignet, von fruchtbaren Forschungen abzulenken.

Der Historiker weiß natürlich, dass er nichts anderes als Repräsentationen des Heiligen $\mathrm{zu}$ fassen bekommt; das gilt auch für die primitive Schicht der Zeugnisse und die autobiographischen Dokumente selbst. Doch auch wenn sich das sirr (Geheimnis) der Heiligkeit seinem Zugriff entzieht, muss er versuchen, sich ihm so weit wie möglich anzunähern. Die Schriften der awliyā, sofern sie ihren eigenen Werdegang beschreiben oder sich bemühen, die walāya zu definieren, verdienen (es) also, aufmerksam studiert zu werden: Aus ihnen kann man nämlich gewisse Erkenntnisse über die beiden erwähnten Kontroversen ableiten. Vor dem Hintergrund einer solchen Untersuchung kann man zumal feststellen, dass die vermeintlich skandalösen Thesen der Tabri'at alDhimma schon seit vielen Jahrhunderten im Umlauf sind und dass shaykh Muhammad 'Utmān somit bestenfalls im weiteren Sinne als Autor dieses Buches gelten darf. In Wirklichkeit handelt es sich dabei im Wesentlichen um eine Zusammenstellung langer Zitate - von dutzenden Seiten zum Teil -, deren Richtigkeit ich Punkt für Punkt überprüfen konnte. Sie stammen aus Werken, die zu einem geringen Teil unveröffentlicht, zumeist aber gedruckt sind und sich ohne größere Schwierigkeiten in Kairo auffinden lassen - was die Kritiker des Gründers der țarīqa burhāniyya selbstverständlich wissen müssten. Ich werde noch auf die Art dieser Texte zurückkommen.

Genau genommen kommt die Heiligkeit allein Gott zu: Der Name al-Quddūs (der einzig Heilige), der von ihr kündet, ist ausschließlich ihm vorbehalten. Für die menschliche Kreatur kann Heiligkeit folglich nichts anderes bedeuten als Teilhabe an der Heiligkeit Gottes. Theologisch gesehen gründet die Möglichkeit dieser Teilhabe auf der Doppelnatur des Namens al-Wali, den der Koran sowohl auf den Menschen wie auf Gott bezieht und der beider Nähe beteuert. Während diese walāya für die meisten Wesen 
reine Möglichkeit ist, ist sie bei einigen verwirklicht. Anthropologisch gesehen begründet der Hadith, dem zufolge Gott Adam 'alā șūratihi, "nach seinem Ebenbild«, schuf, die Fähigkeit des Menschen zum ta'alluh, zur Theomimesis oder größtmöglichen Annäherung an Gott. Der Mensch findet walāya, wenn diese Ähnlichkeit mit Gott wiederhergestellt ist, die er durch seinen Sündenfall fi asfali sāfilīn (Koran 95:5) verloren hat. Seine Verfallenheit aber verbietet ihm den Anblick jenes Gottes, dem er ähnlich sein soll. Er kann seinen ursprünglichen Theomorphismus nur wiedererlangen, wenn er sich dem - in der geschaffenen Welt - einzig unversehrten Bild der göttlichen Form, dem unvergleichlichen Vorbild des takhalluq bi-akhlāq Allāh angleicht, das der Prophet oder besser noch: die haqiqa muhammadiyya oder muhammedanische Wirklichkeit verkörpert.

Der Ausdruck ḥaqiqa muhammadiyya taucht erst sehr spät auf. Ibn al-'Arabī (gest. 538 / 1240-41) gibt ihm Ende des zwölften, Anfang des 13. Jahrhunderts seine Stellung im technischen Vokabular des Sufismus und formuliert die entsprechende Lehre aus. ${ }^{20}$ Doch die Vorstellung, die er zum Ausdruck bringt, hat unter diversen Namen schon einen langen Weg zurückgelegt. Man kann sie bereits bei Ibn Isḥāq (gest. 159 / 768) in einem Bericht über den Vater des Propheten finden: Das Thema des nūr muhammadī, des muhammedanischen Lichts, das bis zu seiner vollkommenen und endgültigen Manifestation in der Person des Muhammad durch die Zeitalter reist, nimmt hier seinen Ausgang. ${ }^{21}$ Gestützt auf die überlieferte Benennung des Gesandten als siräj munir (lichtspendende Lampe) (Koran: 33:46) wird es - etwa von Sahl al-Tustarī ${ }^{22}$ Ḥallāj (gest. $310 / 922-3)^{23}$ und vielen anderen - immer weiter ausgearbeitet und präzisiert. Die Prophetenschaft stellt nichts anderes dar als den äußeren und transitorischen Aspekt der muhammedanischen Funktion (weil nubuwwa und risāla, Prophezeiung und Botschaft, im zukünftigen Leben gegenstandslos sein werden). Das Innere des Propheten ist reine walāya. Bestimmte Autoren werden übrigens in der Folgezeit betonen, dass die uswa hasana nach dem Wortlaut des Koran, fi rasūli llāh, "im" Gesandten Gottes zu suchen ist. ${ }^{24}$ Viel früher aber, im zweiten bzw. achten Jahrhundert, unterscheidet Ja'far Șādiq bei den Gläubigen schon zwischen denjenigen, die dem zāhir (expliziten Wortlaut) des Propheten, und denjenigen, die seinem bāțin (inneren Sinn) folgen. Bei ihm ist Muhammad, wie Paul Nwyia bemerkt, ${ }^{25}$ »das unübertreffliche Vorbild aller Heiligkeit« und nicht nur Richter über das gute Leben oder Paradigma der Tugenden. Auf unterschiedliche Weise bringen viele Texte aus dem dritten und vierten Jahrhundert ähnliche Vorstellungen zum Ausdruck. "Ich tauchte in ein Meer der Glaubenslehren ein, bis ich das Meer des Muhammad erreichte«, erklärt Abū Yazīd alBisțāmī, "und ich sah dann, dass zwischen ihm und mir tausend Stationen lagen und dass ich, wenn ich mich auch nur einer einzigen näherte, im Feuer verbrennen würde«. ${ }^{26}$ Der bewundernswerte - aber leider verstümmelte - autobiographische Bericht, in dem Hakīm al-Tirmidhī seinen Weg zur walāya schildert, bezeugt auf bewegende Weise, dass die spirituelle Vervollkommnung für ihn eine möglichst vollständige Identifikation mit dem Propheten beinhaltet. In einer der Visionen, von denen er erzählt, beschreibt er sich - in fünf Zeilen fünfmal wiederholt - als buchstäblich »in die Fußstapfen « ('alā atharihi) des Gottgesandten tretend. In einer anderen Vision von reicher Symbolik teilt er sein Bett mit dem Propheten. ${ }^{27}$

Diese Auffassung der muhammedanischen Funktion, die in ihrer ganzen Fülle in den Blick genommen wird, ist ganz offensichtlich Kennzeichen einer Elite. Es wäre aber unklug, daraus zu schließen, dass sie nur auf spezifische Milieus beschränkt wäre. Denn auch wenn es einer frommen Literatur - deren berühmtestes Beispiel der Shifā des qāḍī 
'Iyyād ist - sicher an der technischen Genauigkeit und der Durchbildung mangelt, die man in den doktrinalen Abhandlungen findet, von denen noch die Rede sein wird, verbreitet sie doch weitgehend ein Bild des Propheten, über das sich Ibn Taymiyya (gest. 728 / 1327-8) empören wird..$^{28}$ Vor allem aber ist es die Poesie - oft mit gewagten sprachlichen Wendungen, die sich die Prosa versagt -, die zur Übermittlung von Vorstellungen beitragen wird, von denen man glauben könnte, sie beschränkten sich auf enge mystische Zirkel: Das Genre der madā’ih nabawiyya (Elogen auf den Propheten), das durch die seit dem siebten bzw. dreizehnten Jahrhundert sich verbreitende Feier des Mawlid (des Geburtstags des Propheten) zur Blüte gelangt, wird unzählige unbekannte oder berühmte - Dichter inspirieren, deren Werken ein ungeheurer - und übrigens bis heute anhaltender - öffentlicher Erfolg beschert sein wird. ${ }^{29}$

Dennoch wird man gerade in eher theoretischen Werken die explizitesten Formulierungen des prophetischen Modells der Heiligkeit finden. Ibn al-'Arabī spielt in dieser Hinsicht durch seine eigenen Bücher und - indirekt - durch die Bücher seiner Schüler eine entscheidende Rolle, weil er jener Lehre, die den Propheten zum insān kāmil (vollkommenen Menschen) und zum nuskhat al-haqq (Ebenbild Gottes) erklärt, ihren umfassendsten Ausdruck verleiht. ${ }^{30}$ Diese Lehre hat nun aber erhebliche und durch den shayk al-akbar (»den größten Meister« - Bezeichnung des Ibn al-'Arabī; A.d.Ü.) klar bestimmte Konsequenzen für die Modalitäten der spirituellen Verwirklichung: »Die vollkommenste Anschauung Gottes«, so schreibt er, »ist jene, die man in und durch die muhammedanische Form erreicht. ${ }^{31}$ "Versuche nicht, Gott anders als im Spiegel des Propheten zu betrachten «, liest man in einer Abhandlung, die Ibn al-'Arabī nicht mit Sicherheit zugeschrieben werden kann, die aber ganz offenkundig aus der Akbar-Schule stammt. ${ }^{32}$ Die Beziehung dieser Vorstellung zu einer dezidiert prophetenzentrierten Praxis wird noch durch die Tatsache betont, dass Ibn al-'Arabī sie in der erstgenannten Textstelle im Blick auf einen andalusischen Heiligen formuliert, der von Beruf Schmied war, sich aber ausschließlich der ununterbrochenen Rezitation des "Gebets des Propheten" widmete. ${ }^{33}$ Wenn die fuqahă (islamischen Rechtsgelehrten) die vom Propheten eingesetzten Normen verwahren, wie er noch an einer anderen Textstelle des Futūhat erklärt, so verwahren andere Menschen - als Beispiele führt er Dhu l-Nūn al-Miṣrī und Bisțāmī an - seine "Zustände« und "Geheimnisse« ${ }^{34}$ Etwas später erläutert auch Qāshānī in seinen $T a^{\prime}$ wìlāt, dass sich die Orientierung an der uswa hasana nicht auf die Nachahmung der Handlungen des Propheten beschränkt, sondern auch auf die Nachahmung seiner "Zustände« (aḥwāl) und Gotteserscheinungen (tajalliya $\bar{t}$ ) erstreckt. ${ }^{35}$

'Abd al-Karīm al-Jīlī wird dieses Thema im achten bzw. vierzehnten Jahrhundert in all seinen Schriften und insbesondere im Nasim al-Sahar, einem der erhaltenen Teile seiner umfangreichen Abhandlung Nāmūs al-A'zam, in großem Stil weiterentwickeln. ${ }^{36}$ Der Nasim besteht aus zwölf Abschnitten, die sich jeweils auf ein Ereignis im Leben Muhammads beziehen: seine Reise nach Syrien, seinen Rückzug auf den Berg Jabal alNūr, seine letzten Worte etc. Nach al-Jilì muss jedes dieser Ereignisse vom Reisenden (viator) wirklich verinnerlicht werden und darf nicht bloß Gegenstand seiner Meditation bleiben. Es geht hier nicht mehr nur um ein Anteilnahme (adhésion), sondern wirklich um eine Teilhabe (adhérence), und dieser Ausdruck besitzt hier all die Kraft, die er auch im Vokabular des Kardinals Bérulle besaß: Sulūk (das Reisen auf den Pfaden des Propheten) impliziert die Teilhabe des gesamten Wesens an den Zuständen des Propheten. Der sālik (spirituell Reisende) muss daher - nach dem Qāb Qawsayn, einem anderen Fragment des Nāmūs - permanent die șurā (Form) und die haqiqqa (innere 
Realität) Muhammads in sich verwirklichen. Dies nur als Vorschriften zu betrachten, wäre ein Fehler: Al-jīlī stützt sich auf eine persönliche Erfahrung, die ihm den insān kāmil in seinem ganzen Glanz offenbarte und von der er uns in seinen Werken wiederholt berichtet: Im Jahr 796 bzw. 1393 sieht er in Zabīd den Propheten, zunächst von den sieben Attributen des Göttlichen Wesens umhüllt, dann mit diesem Wesen eins geworden. ${ }^{37}$ Eine vergleichbare Vision überkommt ihn im Jahr 802 bzw. 1399 in Medina. ${ }^{38}$ Daher ist der Hinweis nicht uninteressant, dass die »skandalöse" Tabri' $a$ des shayk Muhammad 'Uthmān, die lange, klug ausgewählte Auszüge aus Ibn al-'Arabīs Futūḥat (S. 221-252) akribisch reproduziert und die wiederaufgefundenen Teile von al-jilīs Nāmūs al-A'z̧am (S. 37-74) im vollständigen Text wiedergibt, sich letztlich darauf beschränkt, alten Wein in neue Schläuche zu füllen. ${ }^{39}$

19 Lange vor 'Abd al-Karīm al-Jìlī - einem als weitgehend orthodox geltenden Autor, dessen Werk über alle țuruq hinweg größte Verbreitung erfuhr - hatte schon Ibn 'Atā Allāh (gest. 709 / 1309) beteuert, dass »die haqiqqa muhammadiyya [muhammedanische Wirklichkeit] wie die Sonne ist und die leuchtenden Herzen der awliya [Gottesfreunde] Monden gleichen.$^{40}$ Die muqaddima (Einleitung) seiner Lața $\bar{a}^{\prime}$ if al-Minan ist ein hagiologischer Traktat, der - in verkürzter Form - ganz offensichtlich die Thesen Ibn al-'Arabīs wiedergibt, auch wenn dessen Name nicht erwähnt wird. Hinweise wie die am Ende des ersten Kapitels der Lață'if erscheinen aber noch bedeutsamer, da sie die Rolle des Propheten im Leben bestimmter Heiliger unterstreichen. Dort werden einige der Gefährten des Abū l-Ḥasan al-Shādhilī beschrieben: »Kein anderer als der Gesandte Gottes hat mich erzogen ( $m \bar{a}$ rabbānī illā rasūl Allāh)«, erklärt Makīn al-Dīn al-Așmar. Auch 'Abd al-Rahīm al-Qinawī reklamiert ganz ausdrücklich den Propheten als seinen einzigen Meister. Und was Abū l-'Abbās al-Mursī, den Nachfolger al-Shādhilīs angeht, so erklärt dieser: "Seit vierzig Jahren hat mich kein Schleier vom Gesandten Gottes getrennt. ${ }^{41}$

Andere Persönlichkeiten äußern in derselben Zeit ähnliche Dinge: Dies trifft insbesondere auf zwei der awliyā zu, die von Șafī al-Dīn (gest. 682 / 1283) in seiner Risāla näher gewürdigt werden: auf shayk Abū l-Su'ud und auf shayk Abū l-'Abbās al-Ṭanjī, dem die Fülle muhammedanischer Gelehrsamkeit in Jerusalem unter der Kuppel des Felsendoms zuteilwurde. ${ }^{42}$ Gleichartige Berichte aus späterer Zeit lassen sich in den berühmten Tabaqāt Kubrā von al-Sha'rānī (gest. 973 / 1565) finden. Sie erlauben uns zu verstehen, warum Letzterer in einem anderen Buch mit so viel Nachdruck beteuert, dass »der Gesandte Gottes der wahre Meister (al-shayk al-haqiāi bi-wāsitat ashyākh alțarīq aw bilā wāsița)« ist, »durch Vermittlung der Meister des Wegs oder ohne Vermittler« - diese außerordentliche Gunst, Folge absoluter Treue zur uswa hasana, wurde, so alSha'rānī, unter den ihm persönlich bekannten shuyūkh (Scheichs) dem 'Alī l-Khawwāṣ sowie dem Jalāl al-Dīn al-Suyūṭi (gest. 911 / 1505-6) gewährt. ${ }^{43} \mathrm{Zu}$ den genannten muss man unter den awliyā der mamlukischen Ära beispielsweise noch den Namen des Ibrāhīm al-Matbūlī hinzufügen, von dem die Țabaqāt Kubrā berichten, »dass er keinen shayk außer dem Gesandten Gottes hatte « ${ }^{44}$ oder den des Abū l-Mawāhib al-Sha'rānī, der beteuerte, dass »der Gesandte Gottes mich mit der Kutte des taṣawwuf [Sufismus] bekleidet hat « ${ }^{45}$ Wir haben es hier also mit einer privilegierten Form der Heiligung zu tun, die die islamische Hagiographie sehr früh schon erkannt und beschrieben hat, und die dem Typus uwaysī (ohne persönlichen Kontakt zum spirituellen Lehrmeister; A.d.Ü.) angehört: Ob er nun irdische Meister hat oder nicht - ein sālik dieser Kategorie durchlebt seine spirituelle Lehrzeit tatsächlich unter der Anleitung der rūhāniyya 
(Spiritualität) eines Heiligen oder eines verstorbenen Propheten, und im prominentesten Falle ist es die rūhāaniyya Muhammads, die seine Erziehung übernimmt.

Eine kostbare persönliche Erfahrung trägt übrigens al-Sha'rānī - ebenfalls in den Tabaqāt - an jener Stelle bei, an der er von Nūr al-Dīn al-Shūnī, einem seiner Meister spricht, der für seine extreme Hingabe an den Propheten bekannt ist - er hatte insbesondere die Praxis einer kollektiven Rezitation der taṣliyya (Eulogien) eingeführt. Wiederholt hatte al-Sha'rānī im Traum Nūr al-Dīn al-Shūnī zur Linken des Propheten gesehen. Doch als er eines Tages seinen Meister besuchte, ereignete sich etwas noch Großartigeres: »Der Körper des shayk verschwand«, schreibt er, »und es erschien der Körper des Propheten. «"6 Das Auftreten eines solchen Phänomens ist alles andere als einzigartig: Im Jahr 790 / 1388 erzählt 'Abd al-Karīm al-Jīlī in Zabīd, der Prophet sei ihm in der Gestalt seines Meisters Isma'îl al-Jabartī (gest. 806/1403) erschienen, wobei er daran erinnert, dass der Prophet auch einem der Schüler Shiblīs in dessen Gestalt erschienen wäre. »Bezeuge, dass ich der Gesandte Gottes bin«, befahl Shiblī seinem Schüler - was diese dann auch tat.

22 Mit Shiblī kehren wir ins dritte bzw. neunte Jahrhundert zurück und erkennen bereits hier, dass eine Hagiologie, die den Propheten buchstäblich als al-shayk al-haqiqì auffasst, in einer langen Tradition verwurzelt ist. Dass dieser Prophetozentrismus sogar noch weiter, nämlich bis zur »Auslöschung im Propheten« führen kann, zur al-fanā fïl-nabī, wie es im späteren Sufismus dann heißt, wird durch eine kuriose Anekdote illustriert, die Suyūṭī in einer seiner fatwās $s^{47}$ erzählt: Einer der șahāaba (Gefährten Muhammads) begab sich nach Muhammads Tod zu einer der Ehefrauen des Propheten. Sie hielt ihm den Spiegel vor, den jener zu benutzen pflegte - und da erschien ihm nicht sein eigenes Spiegelbild, sondern das Gesicht des Gesandten. In diesem sehr sachlichen, unkommentiert wiedergegebenen Bericht kündigt sich eine Form der spirituellen Erfahrung an, die viele andere Persönlichkeiten auf die eine oder andere Weise machen werden. In seinem Bericht von einer Vision, die ihn in der Moschee von Medina überkam, erklärt der Emir 'Abd al-Qādir: »Die edle Person des Propheten vermengte sich derart mit der meinigen, dass wir zu einem einzigen Wesen wurden. « ${ }^{48}$

Diese Worte wurden gegen Ende des 13. bzw. 19. Jahrhunderts geschrieben. Aber ich bestehe darauf, dass man in ihnen nicht den Ausdruck eines vermeintlichen Neosufismus sehen darf, der in gewisse turuq ganz neue Formen des Zugangs zur walāya eingeführt hätte: Jede țaīqa ist - vor der Epoche, in der manche eine radikale Veränderung am Werke sehen möchten, ebenso wie nach ihr - in Wirklichkeit eine tarīqa muhammadiyya, auch wenn diese Bezeichnung nicht immer geläufig sein mag. Wenn die Reformatoren des 19. Jahrhunderts neben den langen silsila (spirituellen Kette), die sie alle ohne Ausnahme für sich beanspruchen können, eine kurze silsila, also eine unmittelbare Beziehung zum Propheten reklamieren, so brechen sie deshalb nicht mit der Tradition: Bei allen shuyūkh, die nicht einfach Verwalter des Sakralen sind, sondern als authentische awliyā angesehen werden können, ist die Verbindung oder besser noch: die Vereinigung (irtibāț) mit der rūḥaniyya des Gesandten eine Bedingung für die spirituelle Erfüllung. Die Erfahrung dieser Vereinigung wird in unterschiedlichen Weisen erlebt und mit Hilfe der vielfältigen Ressourcen des symbolischen Repertoires der islamischen Kultur zum Ausdruck gebracht. Da sie aber in der Doktrin begründet ist und im Zeugnis der Meister Bestätigung findet, wird sie als unumgänglich erachtet. Selbst ein Schüler von Ibn Taymiyya wie der Sufi und ḥanbalitische faqīh (islamische Rechtsgelehrte) 'Imād al-Dīn al-Wāsiṭi (gest. 712 / 1312) 
bekräftigt dies. ${ }^{49}$ Im Maghreb des 15. Jahrhunderts werden Jazūlī, der Autor des Dalā'il al-Khayrät, und seine wichtigsten Schüler - auch außerhalb der Gelehrtenzirkel - in dieser Hinsicht beträchtlichen Einfluss ausüben. Ghazwānī, der dritte shaykh der Jazūliyya, gibt einer seiner Schriften bezeichnenderweise den Titel »Der ewige Punkt. Über das Geheimnis des muhammedanischen Wesens« (Al-nuqța l-azaliyya fi sirr al-dhāt al-muhammadiyya). Abū Amr al-Qastālī, ein anderer Jazūlī-shayk, wird vom Abdruck sprechen, den das Bild des Propheten im Herzen des Eingeweihten hinterlässt..$^{50}$ Man sollte sich auch ins Gedächtnis rufen, dass sich Ibn Idrīs, den man gerne als Gründervater des Neosufismus ansieht, über die Vermittlung seines Meisters 'Abd alWahhāb al-Tāzī, Abd al-'Azīz al-Dabbāgh, einem großen Heiligen aus Fès, verbunden ist. ${ }^{51}$ Letzterer beteuert nun ausdrücklich, dass jeder Mensch, der in den Genuss einer Erleuchtung kommt (al-maftūh 'alayhi), sich in großer Gefahr befindet und dem Untergang nahe ist (khațar 'azim wa halak qarib), "solange er die spirituelle Stellung (maqām) des Gesandten nicht erschaut hat«, denn »im edlen Wesen des Propheten wohnt eine ihm eigene Kraft, mit der er [die Kreatur] zu Gott hinzieht «..$^{52}$ Die muhammedanische Meditation erscheint somit auch hier als ein Punkt, an dem der Initiationsweg zwangsläufig vorbeiführen muss.

Unter den Episoden aus dem Leben des Propheten gibt es eine von größter Wichtigkeit, die ich nicht erwähnt habe, als ich auf die von der sira nabawiyya inspirierten hagiographischen Topoi hinwies: Ich meine die Himmelfahrt (mirāj), denn ihr Nachvollzug im Leben des awliya wird von zahlreichen autobiographischen Texten bezeugt, so dass man darin - in der Mehrzahl der Fälle - die Transkription einer wirklichen inneren Erfahrung und nicht bloß eine literarische Imitation sehen sollte. Die Teilhabe an den Zuständen des Propheten findet seinen vollkommensten Ausdruck darin, dass der wali die "nächtliche Reise« rekapituliert, die Muhammad bis an die Schwelle der göttlichen Gegenwart führt. Das früheste Zeugnis einer solchen Erfahrung ist der allgemein bekannte Bericht von Abū Yazīd al-Bisțāmī. ${ }^{53}$ Dennoch finden sich bei Ibn al-'Arabī die genauesten doktrinellen Darstellungen ${ }^{54}$ dieser mi'rāj al-awliyā, aber zugleich auch der differenzierteste persönliche Erfahrungsbericht von den Etappen und dem Ziel dieser Auffahrt zu Gott in Nachfolge des Propheten, die er in mehreren Zeugnissen wiedergibt..$^{55}$ Auch Semnānî ${ }^{56}$ und 'Abd al-Karīm al-Jiillīi ${ }^{57}$ verraten einige Geheimnisse dieser ekstatischen Himmelfahrt. Viele awliyā, die in der Welt weniger bekannt sind, reisen gleich ihnen von einer Himmelssphäre zur anderen dem göttliche Mysterium entgegen: so etwa der Marokkaner 'Abd al-Raḥmān al-Khazraji ${ }^{58}$ oder auch der heilige Patron von Luxor, Abū l-Ḥajjāj al-Uqsurī, dem zugeschrieben wird, er sei dieser übernatürlichen Gunst in der Nacht Mitte des (Monats) Sha'bān teilhaftig geworden. ${ }^{59}$

Doch wie schon gesagt ist die Nachahmung des prophetischen Modells, so vollkommen sie auch sein mag, nie mehr als eine Asymptote. Dies bestätigt sich im Falle der mi riāj der Heiligen. »Unser mi ${ }^{i} r a \bar{j}$ ist nicht mit der seinigen identisch « (inna mi'rājanā laysa kami'rājjihi), erklärt al-Jìlī. ${ }^{60}$ Die körperliche Himmelfahrt bleibt ein Privileg Muhammads: „Die awliy $\bar{a} \lll$, schreibt Ibn al-'Arabī an einer Stelle, an der er die Tabri'a wiedergibt, »unternehmen nächtliche Reisen im Geiste (isrā'at rūḥānniya) [...], ihre Himmelsreisen vollziehen sich nicht in sinnlich-wahrnehmbarer Form." Und am Ende des Berichts über seine eigene Fahrt von einem Himmel zum anderen bis zu dem Ort, den er den "Aufenthalt Muhammads « nennt, präzisiert er: "Ich bin in mir selbst gereist. «"1 Nichtsdestoweniger bleibt die Idee, dass ein wali für sich in Anspruch nimmt, - und sei es auch nur - einen Bruchteil der ganz besonderen, dem Propheten gewährten Gnade 
selbst erfahren zu haben, für die 'ulamā' (islamischen Religionsgelehrten) ein Skandal: So wird im Indien des 16. Jahrhunderts Muhammad Ghawth Gwalyorī, der Verfasser einer Risāla Mírājiyya, wegen Gotteslästerung zum Tode verurteilt und kann sich nur durch überstürzte Flucht retten. ${ }^{62}$ Zahlreiche shuyūkh, denen nach diesen Kriterien dasselbe Urteil gedroht hätte, hatten größeres Glück oder waren vorsichtiger und konnten so dem Blick der Zensoren entgehen. Zwar rührt man mit dem mi'rāj an den äußersten Punkt der sehr reellen, aber auch sehr porösen Grenze zwischen der walāya und der nubuwwa, also zwischen Heiligkeit und Prophetentum. Aber wen könnte es erstaunen, dass in einer Mystik, für die die haqīqa muhammadiyya zugleich Gipfel und Zentrum ist, das innere Abenteuer, das der Pilgerweg zu Gott, das itinerarium in Deum für den wali darstellt, in Anlehnung an jenes Schema erlebt und beschrieben wird, welches ein Text aus dem abendländischen Mittelalter die »Leiter Mohammeds« nennt? Da sind wir nun weit, sehr weit entfernt von unserem Ausgangspunkt - der Melone, die Ibn Hanbal gegessen oder nicht gegessen hat. Mehrere Jahrhunderte Geschichte und eine beträchtliche Zahl von Quadratkilometern habe ich Sie im Galopp - von West nach Ost - durchmessen lassen. Also ein bloßer Überblick, keinesfalls eine erschöpfende Abhandlung. Doch selbst eine methodischere Erforschung der arabischen Quellen wäre wohl unzureichend. Denn die Untersuchung müsste sich auch auf Zentralasien erstrecken (wo insbesondere die Naqshbandiyya seit ihren Anfängen wertvolle Zeugnisse liefert), auf Indien, das ich en passant erwähnte, auf die malaiische Welt, in der die Doktrin des insān kāmil originelle Ausdrucksformen gefunden hat ... Dennoch wage ich es nun, einige Schlussfolgerungen vorzutragen, die in manchen meiner Bemerkungen in Wahrheit schon weitgehend vorweggenommen sind.

Dass man dem shayk Muhammad 'Uthmān in Ägypten einen ungerechten Prozess gemacht hat, ist, wie ich glaube, kaum zu bestreiten: Was immer man über die Vereinbarkeit seiner Lehre mit der Orthodoxie denken mag - und dies ist nicht das Problem, das uns hier beschäftigt -, so ist diese Lehre doch in keiner Weise provokativ. Einer seiner ersten Schüler übergab Valérie Hoffman ein Exemplar der Tabri' $a$ und erklärte ihr, sehr zu Recht: »Muhammad 'Uthmān hat dieses Buch nicht geschrieben. Es ist das Werk von mehr als achtzig Autoren. ${ }^{63}$ Erstaunlich an diesem Vorgang ist nicht etwa, dass die üblichen Gegner des Sufismus diese banale Textsammlung erbittert attackierten - sondern, dass auch die Würdenträger des offiziellen »Obersten SufiRates« sie mit derselben Heftigkeit anprangerten. In der Person des sudanesischen shaykh wurden eigentlich die Meister, die er für sich in Anspruch nimmt, ins Visier genommen und ein überreiches, bemerkenswertes Erbe über Bord geworfen. Eine Bestätigung dieser Haltung - die auf Kritiken fundamentalistischer Bewegungen mit einer selbstmörderischen Überbietung ebendieser Kritiken antwortet - findet man beispielsweise in einem 1992 veröffentlichten Interview mit Muḥammad Zakī Ibrāhīm, dem Oberhaupt des Sufi-Ordens țāriqa muhammadiyya shādhiliyya: ${ }^{64}$ Für ihn vertreten Autoren wie Ibn al-'Arabī oder al-Jīlì einen Sufismus, der »dem Islam fremd ist«. Aber er versichert mit Genugtuung: "Sie haben heute weder Schüler noch Erben.« Eine offensichtlich falsche Behauptung, wie schon die Existenz der Burhāniyya und auf diskretere Weise auch die Existenz weniger lautstarker, doch unbezweifelbar legitimer turuq zeigt. Zugleich offenbart diese Behauptung aber den Bruch zwischen der Fassade eines durch die Epigonen des Ibn Taymiyya beeinträchtigten institutionellen Sufismus und den sehr alten Gewissheiten, die in den Tiefen der umma (Gemeinschaft der Muslime) unaufhörlich neue Leidenschaften entfachen. 
se Gewissheiten und Leidenschaften hatten die Väter des »Neosufismus« selbst als Erbe übernommen. Reformatoren waren sie zweifellos. Ist aber die Geschichte der turuq - ebenso wie die der Mönchsorden - nicht einfach die Geschichte stets aufs Neue einsetzender Reformen? In Umkehrung einer wohlbekannten Redensart, die im Okzident die Ausnahmestellung der Kartäuser veranschaulicht, könnte man behaupten, dass die Grundregel jeder țariqā »semper deformata, semper reformata" lauten müsse. Jedes Jahrhundert erlebt das Wirken von Meistern, die sich unter den jeweiligen Bedingungen ihrer Epoche und ihres Milieus daran machen, den ursprünglichen Elan wiederzubeleben und das besondere Charisma, das die Daseinsberechtigung ihres Wegs ausmacht, wieder klar herauszustellen. Um den aktuellen Herausforderungen zu begegnen, muss man den einen oder anderen Aspekt der Glaubenssätze oder Praktiken betonen - andere Worte finden, um dieselben Dinge zu sagen. Doch das Auftauchen einer țāriqa mit ganz neuem Namen darf uns nicht täuschen. Der "Neosufismus" ist kein Mythos, wenn man darunter versteht, dass das ausgehende 18. und das beginnende 19. Jahrhundert von namhaften Figuren geprägt waren - Tijānī, Sanūsī, Mirghānī, Mawlānā Khālid, Mawlāy al-'Arabī l-Darqawī -, die sehr alten Traditionen neues Leben einhauchten. Er wird aber zu einer reinen Fiktion, wenn man ihn von jenen Wurzeln abzuschneiden versucht, die seine Meister niemals verleugnet haben.

Ich werde hier nicht auf die neun Besonderheiten eingehen, die nach Radtkes und O'Faheys Analyse die Originalität ausmachen, die manche Wissenschaftler um jeden Preis im Neosufismus erkennen wollen. Ein einziger Punkt ist für mein Vorhaben von unmittelbarem Interesse: der unentbehrliche Bezug auf den Propheten in der Lehre dieser Reformatoren. Die hier zitierten Beispiele zeigen hinlänglich, wie mir scheint, dass dieser Bezug - in einfachen oder gelehrten, gewundenen oder expliziten Formen aus einem ganz einfachen Grund immer fundamental war: weil nämlich die Heiligkeit ohne ihn im Islam nicht denkbar ist. Zwischen Gott und dem Menschen ist der Prophet der barzakh, die Schranke oder der Isthmus, der die kreatürlichen Wirklichkeiten mit den himmlischen Wirklichkeiten verbindet und den Übergang von den einen zu den andern ermöglicht. ${ }^{65} \mathrm{In}$ ihm erstrahlt dieses sichtbare Bild des unsichtbaren Gottes, das jeder Sohn Adams in sich selbst wiederherzustellen aufgerufen ist. Die Wiederherstellung dieses durch den Sündenfall zerstörten Theomorphismus kann also nur darin bestehen, sich mit dem Propheten in Übereinstimmung zu bringen, der der einzig wahre Meister und das einzig makellose Vorbild ist. Die Vereinigung mit der rūhaniyya des Gesandten, die Entwerdung in ihr, ist der einzige Weg zur Entwerdung in Gott. Jenseits der naiven Abziehbilder der Hagiographie bleibt die uswa hasana für den Historiker der Heiligkeit im Islam folglich ein unverzichtbarer Bezugspunkt. Sie erklärt nicht alles, aber ohne sie lässt sich nichts erklären. Die Aufmerksamkeit auf diese Invariante darf sicherlich nicht dazu führen, die Variablen $\mathrm{zu}$ vergessen. Doch umgekehrt reichen die Idiosynkrasien des wali, die Eigentümlichkeiten seiner Umgebung, die Kontingenzen der lokalen Geschichte niemals aus, um sich das Phänomen der walāya zu vergegenwärtigen, solange man vergisst, dass der Prophet im Islam der Spiegel Gottes, der Heilige aber Spiegel des Propheten ist. 


\section{BIBLIOGRAPHIE}

'Abd al-Qādir al-Jazā'irī, A. (1967): Kitāb al-Mawāqif, Bd. 1, Damaskus: Dar al-Yaqzā al-'Arabiyā.

'Abd al-Qādir al-Jazā'irī, A. [Abd el Kader, Emir] (1982): Écrits spirituels, hg. u. übers. von Michel Chodkiewicz, Paris: Seuil.

Al-Taṣawwuf al-Islāmī, August 1992.

Anawati, G. C. / Gardet, L. (1963): Mystique musulmane. Aspects et tendances. Expériences et techniques, Paris: Librairie Philosophique J. Vrin.

Andrae, T. (1917): Die Person Muhammeds in Lehre und Glauben seiner Gemeinde, Leipzig: O.

Harrassowitz.

'Aydarūs, A.B. al- (1976): al-Quțb al-kabīr al-Rifā'i, aw al-Najm al-sā' î fi manāqib al-qutb al-kabìr alRifā'ī, Kairo: Maktabat al-Kulliyāt al-Azhariyah.

Azma, N. al- (1973): "Some notes on the impact of the story of the mi'rāj on Șufĩ litterature«, The Muslim World 63, S. 93-104.

Badawī, A. R. (1949): Shataḥ̄āt al-Ṣūfiyya, Kairo: Maktabat al-naḥda al-Mișriyya.

Baldick, J. (1998): Mystical Islam: An Introduction to Sufism, London: I. B. Tauris \& Co Ltd.

Böwering, G. (1980): The Mystical Vision of Existence in Classical Islam: The Qur'ānic hermeneutics of the Șūfi Sahl at-Tustarī, (d. 283 / 896), Berlin / New York: de Gruyter.

Boullata, I. J. (1981): »Toward a biography of Ibn al-Farid«, in: Arabica 28, S. 38-56.

Carra de Vaux, B. (1913-1938): »Walī«, Encyclopédie de l'Islam, Leiden / Paris: Brill / Maisonneuve et Larose.

Burhānī, M.'U. al- (1974): Tabri'at al-dhimma fī nuṣh al-umma wa-tadhkirat ūlī l-albāb li-l-sayr ilā lșawāb, Khartoum.

Chih R. (1993): »Abū l-Ḥajjāj al-Uqsurī, saint patron de Louqsor«, in: Egypte - Monde Arabe 14, S. 67-77.

Chodkiewicz, M. (1986): Le sceau des saints. Prophétie et sainteté dans la doctrine d'Ibn Arabī, Paris: Gallimard.

Corbin, H. (1972): En Islam iranien, Bd. 3: Aspects spirituels et philosophiques, Paris: Gallimard.

Cornell, V. J. (1989), Mirrors of Prophethood: The Evolving Image of the Spiritual Master in the Western Maghreb from the Origins of Sufism to the End of the Sixteenth Century, Dissertation, University of California, Los Angeles.

Ḥaqqī, I. (1330h. / 1912): Rūḥ al-Bayān, Bd. 7, Istanbul: Maṭba'ah ‘Uthmānīyah.

Hoffman-Ladd, V. J. (1992): »Devotion to the Prophet and his Family in Egyptian Sufism«, International Journal of Middle East Studies 24, S. 615-637.

Hoffman, V. J. (1995): Sufism, Mystics, and Saints in Modern Egypt, Columbia: University of South Carolina Press.

Homerin, T. E. (1994): From Arab Poet to Muslim Saint: Ibn al-Farid, His Verse, and His Shrine, Columbia: University of South Carolina Press. 
Ibn al-'Arabī, 'A. (1329h. / 1911): Al-Futūḥāt al Makkīyah, Kairo: Dār al-Kutub al-'Arabìyah alKubrā.

Ibn al-'Arabī, 'A. (1968): Tafsīr al-Qur'ān, Bd. 2, Beirut: Dār al-yaqaẓah al-'Arabīyah.

Ibn al-'Arabī, 'A. (1987): Tanbīhāt 'alā 'Uluww l-Haqīqa l-Muhammadiyya, Kairo: Makbata 'Ālarn alFikr.

Ibn al-'Arabī, M. (1409h. / 1989): Risālat Rūḥ al-qudus, hg. von Badawī Ṭāhā 'Allām, Kairo: 'Ālam alFikr.

Ibn al-'Arabī, 'A. (1988): La vie merveilleuse de Dhū l-Nūn l'Égyptien [Kawkab Durrī], übers. von R. Deladrière, Paris: Sindbad.

Ibn al-'Arabī, 'A. (1989): Les illuminations de la Mecque, übers. von M. Chodkiewicz, Paris: Albin Michel.

Ibn al-Jawzī, 'A. (1986): Sifat as-Safwa, Bd. 2, Beirut: Dār al-Ma'rifa.

Ibn al-Ṣabbāgh, M. (o. J.): Durrat al-Asrar, Qus: Qinā Dār Āl-ar-Rifāi

Ibn Hishām (1955): Sïra Nabawiyya, hg. von Mustapha al-Saqqa, Ibrahim al-Ibyari und Abdel Hafiz Shalabi, Bd. 1, Kairo: Al-Bābī al-Ḥalabī.

Ibn Zāâir, Șafī l-Dīn b. Abī al-Manșūr (1986: La risāla de Șafī al-Dīn ibn Abī l-Manșūr ibn Ẓāfir, Institut Français d'Archeologie Orientale, übersetzt und hg. von Denis Gril, Kairo.

'Iyyad, Q. (1977): Al-shifā bi-Ta' rîf Ḥuqūq al-Mușțafāa, hg. von Ali Muhammad al-Bajawi, Beirut: Dar al-Kitab al-'Arabi.

Jìlī, ‘A. al- (1963): Insān Kāmil, Kairo: NN.

Jìlī, 'A. al- (o. J.): Al-Kahf wa l-Raqim, Ms. Berlin We 1631.

Jìlī, 'A. al- (o. J.): Al-Kamālāt al-Ilāhiyya, Ms. Dār al-Kutub, Taṣ 360.

Kaptein, N. (1993): Muhammad's Birthday Festival: Early History in the Central Muslim Lands and Development in the Muslim West until the $10^{\text {th }} / 16^{\text {th }}$ Century, Leiden: Brill.

Kattānī, M. al- (1316h. / 1898-9): Salwat al-Anfās, Bd. 2 u. 3, Fes.

Luizard, P. J. (1991): »Le rôle des confréries soufies dans le système politique égyptien«, Monde Arabe: Maghreb-Mashrek 131, S. 26-53

Mayeur-Jaouen, C. (1992): Al Sayyid Ahmad al-Badawī, literaturwissenschaftliche Doktorarbeit, Bd. 1 , Paris IV.

Massignon, L. (1975): La passion de Husayn ibn Mansûr Hallâj, martyr mystique de l'Islam exécute à Bagdad le 26 mars 922: étude d'histoire réligieuse, Bd. 3: La doctrine de Hallâj, Paris: Gallimard.

Meddeb, A. (1989): Les dits de Bisțāmī, Paris: Fayard.

Mubārak, A. al- (1984): al-Ibrīz min kalām Sayyidī 'Abd al-'Azīz al-Dabbāgh, Bd. 1, Damaskus: alMața'ah al-'Āmmiyah.

Nwyia, P. (1970): Exégèse coranique et langage mystique. Nouvel essai sur le lexique technique des mystiques musulmans, Beirut: Dar el-Machreq Éditeurs.

O'Fahey, R. S. (1990): Enigmatic Saint: Ahmad Ibn Idris and the Idrisi tradition, London: Hurst \& Co.

Qațtan, A. al-/ Zayn, M. al- (1988): Hārūn al-Rashìd: al-khalifah al-maẓlūm, Kuweit: Tawzī' Maktabat al-Manār al-Islāmìyah. [Chodkiewicz gibt aber als Titel Imām al-Tawhìd, an!] 
Radtke, B. / O’Fahey, R. S. (1993): »Neo-Sufism Reconsidered «, Der Islam. Journal of the History and the Culture of the Middle East 70, S. 52-87. [https://doi.org/10.1515/islm.1993.70.1.52]

Rizvi, S. A. (1983): A History of Sufism in India, Bd. 2: From Sixteenth Century to Modern Century, New Delhi: Munshiram Manoharlal.

Rubin, V. (1975): »Pre-existence and light: Aspects of the concept of Nur Muhammad«, in: Israel Oriental Studies 5, S. 62-119.

Sammān, M. 'A. al- (1977): Ta’thīm al Dhimma fi Taḍlil al-Umma, Kairo: Dār Ḥarrā'.

Sarrāj, A. al- (1960): Kitāb Al-Luma', Bagdad: Maktabat al-Mulhanna.

Scattolin, G. (1998) »Sufism and law in Islam: A text of Ibn 'Arabî (560/1165-638/1240 on

>Protected People` (Ahl al-dhimma)«, Islamochristiana, Bd. 24, Dirasāt Islāmiyya Masīhiiyya, S. 3755.

Schimmel, A. (1981): Und Mohammed ist sein Prophet. Die Verehrung des Propheten in der islamischen Frömmigkeit, Düsseldorf / Köln: Diederichs.

Semnānī, A. (1990), Sirr Bāl al-Bāl li-Dhawī l-Ḥāl, Muṣannafāt-i Farsī, Teheran.

Ibn 'Ațā'allāh al-Iskandarī (1375h/1938): Lațā' if al-minan, Kairo: [ohne Verlag].

Sha'rānī, 'A. al- (1954): Aț-Tabaqāt al-kubrāa, Kairo: Dār al-'ilm li-ăl-ğamī' .

Sha'rānī, 'A. al- (1961): Lawaqịh al-Anwār al-Qudsiyya, Kairo: al-Bābī al-Ḥalabī.

Shațțanawfī, N. (1330h. / 1912): Bahjat al-Asrar, Kairo: Al-Bābī al-Ḥalabī.

Suṭūḥī, M. al- (1976): Interview in Al-Ahrām vom 9. Januar 1976.

Suyūṭī, 'A. al- (1959): Al-Ḥ̄āwì lil-Fatāwī, Bd. 2, Kairo: Maṭba'at as-Sa'āda.

Tirmidhī, H. (1965): Khatm al-Awliyā, hg. von O. Yahia, Beirut: Imprimerie catholique.

Imād al-Dīn Aḥmad al-Wāsițī l-Baghdādī, Al-Sulūk wa l-Sayr ilā Llāh, Ms. Zāhiriyya 4709.

Wensinck, A. J. (1992 [1933-1969]): Concordance et indices de la tradition musulmane, Leiden: Brill.

Yāfi'ī, A. (1955): Raw ạ al-Rayāḥīn, Nr. 489, Kairo: Al-Bābỉ al-Ḥalabī.

\section{NOTES}

1. Ibn al-Jawzī (1986), S. 345.

2. Das gilt insbesondere für Ibn al-'Arabī; vgl. beispielsweise ders. (1329), S. 247, sowie die französische Übersetzung des Kawkab Durrī (1988), S. 196.

3. Auch wenn man nicht weiß, wie der Prophet Melonen aß, so ist doch mindestens verbürgt, dass er sie aß. Vgl. Wensick 1992 [1933-1969], Bd. 1, S. 189, mit Verweisen auf die Hadithe, die sich bei Abū Dāwūd, Tirmidhī und Ibn Mājah finden.

4. Es ist diese Sure, die den Propheten als khātam al-nabiyyīn (Siegel der Propheten) und als sirāj munir (lichtspendende Lampe) bezeichnet, und sie instituiert auch die șalāt 'ala l-nabì (das Gebet des Propheten).

5. Wensinck (1992 [1933-1969]), Bd. 2, S. 75.

6. Schimmel (1981).

7. Schimmel (1981), S. 32.

8. Andrae (1917). Vgl. hingegen unter den jüngeren Publikationen das Buch von Kaptein (1993) und den ausgezeichneten Artikel von Hoffman-Ladd (1992). 
9. Anawati / Gardet (1963); Baldick (1998); Islamochristiana, S. 11. In Niz̄āmīs Artikel »Models of holiness« geht es natürlich auch um das am Propheten orientierte Modell, es ist aber ausschließlich aus ethischer Perspektive behandelt.

10. Luizard (1991), S. 131. Ergänzende Informationen findet man in dem in Anm. 8 erwähnten Aufsatz von V. Hoffman-Ladd sowie insbesondere im 9. Kapitel ihres Buchs Sufism, Mystics, and Saints in Modern Egypt.

11. Hinsichtlich der Vorwürfe gegen die Begründer der Burhāniyya siehe Sammān (1977) und unter anderen Artikeln - das Interview mit Suṭūhī (1976).

12. Der Islam 70 (1993), S. 52-87. Siehe auch R. S. O’Faheys (1990) Werk über Ahmad ibn Idris alFasi, Kap. 1 .

13. Mayeur-Jaouen (1992), S. $170 \mathrm{f}$.

14. Qațtan / Zayn (1988), S. 35.

15. Shațțanawfī (1330h.), S. 21; Aydarūs (1976), S. 25.

16. Yāfi'î̀ (1955), S. 460; Kattānī (1316h.), Bd. 2, S. 248.

17. Boullata (1981), S. 49. Ich konnte bisher weder das Werk von Homerin (1994) noch den demnächst in Islamochristiana erscheinenden Artikel von Scattolin (1998) konsultieren.

18. Die Begegnung mit einem rāhib ist ein Thema, das man auch bei Ibn al-'Arabī findet (der in diesem Zusammenhang ältere hagiographische Berichte überträgt. Siehe beispielsweise Ibn al'Arabī (1329h.), Bd. 1, S. 223 f.; ebd., Bd. 4, S. 511, 522 f., 549; sowie Ibn al-'Arabī (1988), S. 345-348. 19. Ibn al-Șabbāgh (o. J.), S. 34 f.

20. Ich gehe auf diesen Punkt im 5. Kapitel von Le sceau des saints (Chodkiewicz 1986) ein.

21. Ibn Hishām (1955), S. 155. Vgl. auch den Aufsatz von Rubin (1975).

22. Siehe Böwering (1980), 4. Kap.

23. Siehe Insbesondere die Übersetzung des Kitāb al-Tawāsīn in Massignon (1975), S. 304-306.

24. Haqqī (1330h.), S. 156.

25. Nwyia (1970), S. 183-190.

26. Badawī (1949), S. 66. Die Übersetzungen, die Meddeb (1989), S. 41, von diesem wie auch von einem ähnlichen Passus anbietet (Badawī [1949], S. 86; Meddeb [1989], S. 74), müssen korrigiert werden.

27. Tirmidhī (1965), S. 16 u. 28.

28. 'Iyyad (1977), inbesondere S. 546-559.

29. Naskhat al-Haqq lautet übrigens der Titel einer bis heute unveröffentlichten kleinen Abhandlung des Ibn al-'Arabī, die die akbarianische Lehre des insān kāmil rekapituliert.

30. Nuskhat al-haqq ist übrigens auch der Titel eines kleinen, bis heute nicht im Druck veröffentlichten Traktats Ibn al-'Arabīs, der Akbars Lehre vom insān kāmil rekapituliert.

31. Ibn al-'Arabī (1329h.), Bd. 4, S. 184.

32. Tanbīhāt 'alā 'Uluww l-Haqīqa l-Muhammadiyya, unter dem Namen Ibn al-'Arabīs veröffentlicht. Vgl. Ibn al-'Arabī (1987), S. 34.

33. $\mathrm{Zu}$ dieser Persönlichkeit, die man daher nur unter dem Namen »Ṣallī 'alā Muhammad" kannte, siehe auch Ibn al-'Arabī, M. (1409h. / 1989): Risālat Rūh al-qudus, hg. von Badawī Ṭāhā 'Allām, Kairo: ‘Ālam al-Fikr.

34. Ibn al-'Arabī (1329h.), Bd. 1, S. 151.

35. Vgl. Tafsìr al-Qur'ān (unter dem Namen Ibn al-'Arabīs veröffentlicht) in Bezug auf Vers 33:21; hier als Ibn al-'Arabī (1986), S. 286.

36. Der Nasìm al-Sahar liegt in einer in Kairo (ohne Jahr) veröffentlichten Edition vor.

37. Jìlī (o. J.), Al-Kahf wa l-Raqìm, f. 222a.

38. Jīlī (o. J.), Al-Kamālāt al-Ilāhiyya, f. 58.

39. Die Tabri'a gibt gleichermaßen (auf S. 75 f.) das Ende des abschließenden 63. Kapitels von alJìlī (1963), Bd. 2, S. 146 ff. wieder. Wir möchten darauf hinweisen, dass die von Muhammad 
'Uthmān angeführten Zitate aus dem Futūhat sich auf die Ausgabe von 1293 und nicht auf die weiter verbreitete - von 1329 von beziehen.

40. Ibn 'Atā Allāh (1375h / 1938), Lațā'if al-Minan, als Marginalie des gleichnamigen Werks von Sha'rānī., S. 20. Siehe auch eine entsprechende Formulierung auf S. 6.

41. Ibn 'Atā Allāh (1375h / 1938), Lațâ'if al-Minan, , S. 97. Das Zitat von Abū l-'Abbās al-Mursī Sha'rānī in: ders. (1954), S. 14.

42. Gril (1986), ff. $91 \mathrm{~b}$ und 125b.

43. Sha'́rānī (1961), S. 5.

44. Sha'rānī (1954), S. 83.

45. Ebd., S. 73.

46. Ebd., S. 172.

47. Suyūṭī (1959), S. 438f. Al-Suyūṭī, der sonst präzisere Angaben macht, merkt zu dem hier genannten Gläubigen lediglich an: »Ich glaube, es handelte sich um Ibn 'Abbas.« Und hinsichtlich der Ehefrau des Propheten: »Ich glaube, es handelte sich um Maymūna.« Ich habe al-Suyūṭis Quelle nicht identifizieren können.

48. 'Abd al-Qādir al-Jazā'irī (1967), S. 47. Dieses 13. Kapitel des Werks habe ich in Abd el-Kaders Écrits spirituels übersetzt. Vgl 'Abd al-Qādir al-Jazā'irī [Abd el-Kader] (1982), S. 164.

49. 'Imād al-Dīn Aḥmad al-Wāsițī l-Baghdādī, Al-Sulūk wa l-Sayr ilā Llāh, Ms. Zāhiriyya 4709.

50. Über die Rolle der Jazūliyya bei der Verbreitung des prophetischen Modells der Heiligkeit im Maghreb vgl. die Dissertation von Cornell (1989), Kap. 7-9.

51. Siehe O'Fahey (1990), S. $40 \mathrm{f}$.

52. Mubārak (1984), S. 400; vgl. auch S. 55.

53. Zum mi'rāj Bisțāmīs vgl. Sarrāj (1960), S. 464; Badāwi (1949), S. 116 sowie den Artikel von Azma (1973).

54. Vgl. dazu insbesondere Ibn al-'Arabī, (1329h.), Bd. 3, S. 52, Kap. 314 und S. 208, Kap. 349.

55. Vgl. Chodkiewicz (1986), Kap. 10. Dort werden die maßgeblichen Texte analysiert: Kap. 167 und 367 der Futūhat sowie die Risālat al-Anwār. Umfangreiche Auszüge aus Kap. 367 wurden von J. W. Morris ins Englische übersetzt, in: Ibn al-'Arabī (1989), S. 351-381.

56. Semnānī (1990), S. 127-151. Vgl. auch Corbin (1972), S. 346 f.

57. Jilīi (1963), Kap. 49 und 62.

58. Kattānī, (1316h.), Bd. 3, S. $18 \mathrm{f}$.

59. Chih (1993). Die Autorin präzisiert jedoch, dass nach al-Udfuwī, der ihm eine Notiz widmet, der mírāj Abū l-Ḥajjājs nur eine von unwissenden Schülern verbreitete Legende sei. Diese Legende, wenn sie denn eine ist, ist heute jedenfalls immer noch sehr lebendig.

60. Jìlī (1963), Bd. 2, S. 8.

61. Ibn al-'Arabī (1329h.), Bd. 3, S. 342f. für das erste Zitat Burhānī, M.'U. al- (1974), S. 250. und S. 350 für das zweite.

62. Rizvi (1983), S. 157-159.

63. Hoffman-Ladd (1995), Kap. 9.

64. Al-Tașawwuf al-Islāmī, August 1992, S. 43.

65. Vgl. Ibn al-'Arabī, II, 391 und 396, wo die Funktion des insān kāmil in diesen Begriffen beschrieben wird. 
INDEX

Schlüsselwörter : Heiligkeit, Islam, Prophet, imitatio prophetae

Mots-clés : sainteté, islam, prophète, imitatio prophetae

\section{AUTEURS}

\section{MICHEL CHODKIEWICZ}

Michel Chodkiewicz ist Verleger und Spezialist des Sufismus. Nähere Informationen finden Sie hier. 